\title{
Eckol Alleviates Intestinal Dysfunction during Suckling-to-Weaning Transition via Modulation of PDX1 and HBEGF
}

\author{
Sang In Lee ${ }^{1}$ and In Ho Kim ${ }^{2, *}$ \\ 1 Department of Animal Biotechnology, Kyungpook National University, Gyeongsangbuk-do, \\ Sangju 37224, Korea; silee78@knu.ac.kr \\ 2 Department of Animal Resource and Science, Dankook University, Chungcheongnam-do, \\ Cheonan-si 330-714, Korea \\ * Correspondence: inhokim@dankook.ac.kr; Tel./Fax: +82-41-550-3652
}

Received: 8 June 2020; Accepted: 2 July 2020; Published: 3 July 2020

\begin{abstract}
Maintaining intestinal health in livestock is critical during the weaning period. The precise mechanisms of intestinal dysfunction during this period are not fully understood, although these can be alleviated by phlorotannins, including eckol. This question was addressed by evaluating the changes in gene expression and intestinal function after eckol treatment during suckling-to-weaning transition. The biological roles of differentially expressed genes (DEGs) in intestinal development were investigated by assessing intestinal wound healing and barrier functions, as well as the associated signaling pathways and oxidative stress levels. We identified 890 DEGs in the intestine, whose expression was altered by eckol treatment, including pancreatic and duodenal homeobox (PDX)1, which directly regulate heparin-binding epidermal growth factor-like growth factor (HBEGF) expression in order to preserve intestinal barrier functions and promote wound healing through phosphoinositide 3-kinase (PI3K)/AKT and P38 signaling. Additionally, eckol alleviated $\mathrm{H}_{2} \mathrm{O}_{2}$-induced oxidative stress through PI3K/AKT, P38, and 5'-AMP-activated protein kinase (AMPK) signaling, improved growth, and reduced oxidative stress and intestinal permeability in pigs during the weaning period. Eckol modulates intestinal barrier functions, wound healing, and oxidative stress through PDX/HBEGF, and improves growth during the suckling-to-weaning transition. These findings suggest that eckol can be used as a feed supplement in order to preserve the intestinal functions in pigs and other livestock during this process.
\end{abstract}

Keywords: barrier function; eckol; HBEGF; ethanol extract of dried E. cava

\section{Introduction}

The suckling-to-weaning transition contributes to intestinal dysfunction in livestock, which undermines animal health, growth, and feed intake [1]. During this transition, the intestine undergoes marked physiologic changes in structure and function, including villous atrophy and crypt elongation, which decrease its absorptive capacity, thereby influencing feeding efficiency [2-4]. Alleviating intestinal dysfunction during this process is important, given the direct relationship between animal health and economic productivity.

The intestinal epithelium is composed of single-layered columnar epithelial cells that are sealed by junctional complexes, including tight and adherens junctions, in close proximity to the apical and lateral sides of the paracellular space [5]. It functions as a barrier against harmful substances, including pathogenic bacteria and food allergens [6]. Intestinal dysfunction that is induced by the suckling-to-weaning transition can disrupt these junctional complexes, thereby allowing for the passage of macromolecules and pathogens through the epithelium into the body, which can influence 
animal growth and health status [7,8]. Preserving intestinal health minimizes the adverse effects of weaning-induced stress. To this end, nutritional strategies, such as optimizing dietary proteins or energy content and the use of feed additives, have been implemented [9-11]. Antibiotics, as feed additives, are broadly used in the pig industry to enhance intestinal health that is challenged by weaning-induced stress. Many alternatives, including probiotics, organic acids, and polyphenols, are used as substitutes due to a ban on antibiotic use in feedstuffs, although in-feed antibiotics are used to reduce weaning-induced stress and enhance growth performance [12-14]. Among these candidates, polyphenols may have the greatest potential to enhance gut intestinal health [15].

Polyphenols have been investigated for their potential in promoting gut health and regulating the intestinal nutrient absorption, as well as lipid and bone metabolism [16]. Phlorotannins are oligomeric polyphenols that consist of phloroglucinol units that are found in brown algae (Ecklonia sp.), including Eckolina cava; this is an edible marine brown alga species found in the ocean off the coasts of Japan and Korea. These compounds have anti-diabetic, anti-cancer, antioxidant, antibacterial, and radio-protective properties, as well as inhibitory effects against HIV [17-20]. A previous report showed that compounds isolated from the ethanol extract of dried E. cava (EEEC), including phloroglucinol, eckol, phlorofucofuroeckol, and dieckol, exhibit strong antiviral activity against porcine epidemic diarrhea virus by inhibiting viral entry and/or replication, and suppressing adipogenesis by downregulating $\mathrm{C} / \mathrm{EBP} \alpha$ in adipocytes [21,22]. In addition, a previous report suggested that E. cava has beneficial effects on growth performance, cecal microflora, and intestinal morphology in weaning pigs [23]. However, to our knowledge, there is no study investigating the effects of these compounds on the intestinal function of piglets during the suckling-to-weaning transition, as this is the most active period of small intestinal epithelium development.

To this end, we evaluated the effects of EEEC on the small intestine during the said transition period by gene expression profiling. Differentially expressed genes (DEGs) upon EEEC treatment were further analyzed in order to determine their roles in small intestine development.

\section{Results}

\subsection{Identification and Validation of DEGs}

We used high-throughput sequencing to identify DEGs that were expressed in response to EEEC by comparing the gene expression profiles of small intestinal tissue with or without EEEC treatment for $14 \mathrm{~d}$. Of the 890 annotated DEGs, 639 were upregulated and 251 were downregulated (Figure 1A).

A gene ontology (GO) enrichment analysis showed that DEGs were related to calcium, heme, iron, heparin, carbohydrate, and lipid binding, as well as chemokine, transporter, serine-type endopeptidase inhibitor, and hormone activities (Supplemental Table S1). Genes within the "cellular component" category were mainly associated with the "extracellular region", "integral component of plasma membrane", "cell surface", and "cell" terms (Supplemental Table S2), whereas the "biological process" terms included "inflammatory response", "immune response", "innate immune response", "oxidation-reduction process", "cell surface receptor signaling pathway", "cell adhesion", "cytokine-mediated pathway", "response to lipopolysaccharide", and "chemokine-mediated signaling pathway" (Supplemental Table S3). The Kyoto Encyclopedia of Genes and Genomes pathway analysis showed that the proteins were mainly associated with the following categories: cytokine-cytokine receptor, neuroactive ligand-receptor, and extracellular matrix-receptor interactions; peroxisome proliferator-activated receptor $\gamma$, chemokine, Janus kinase-signal transducer and activator of transcription (STAT), tumor necrosis factor, Toll-like receptor, and transforming growth factor (TGF)- $\beta$ signaling; inflammatory bowel disease (IBD); and, retinol metabolism (Supplemental Table S4). 
A

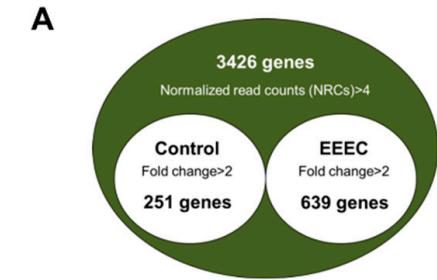

C

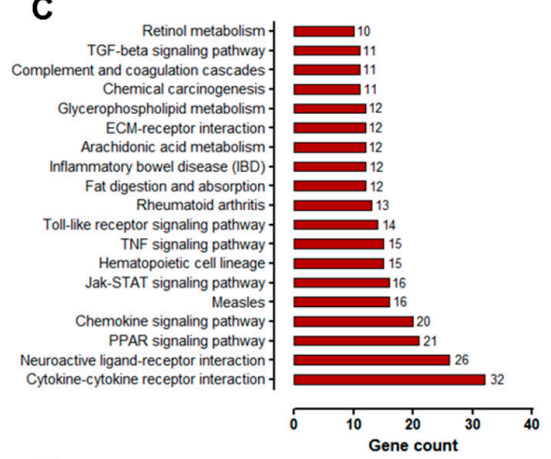

D

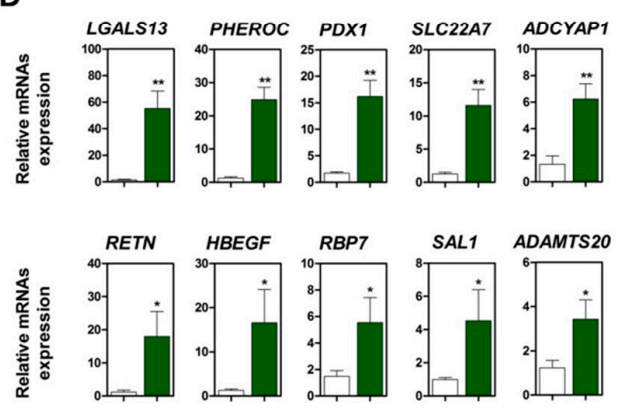

B

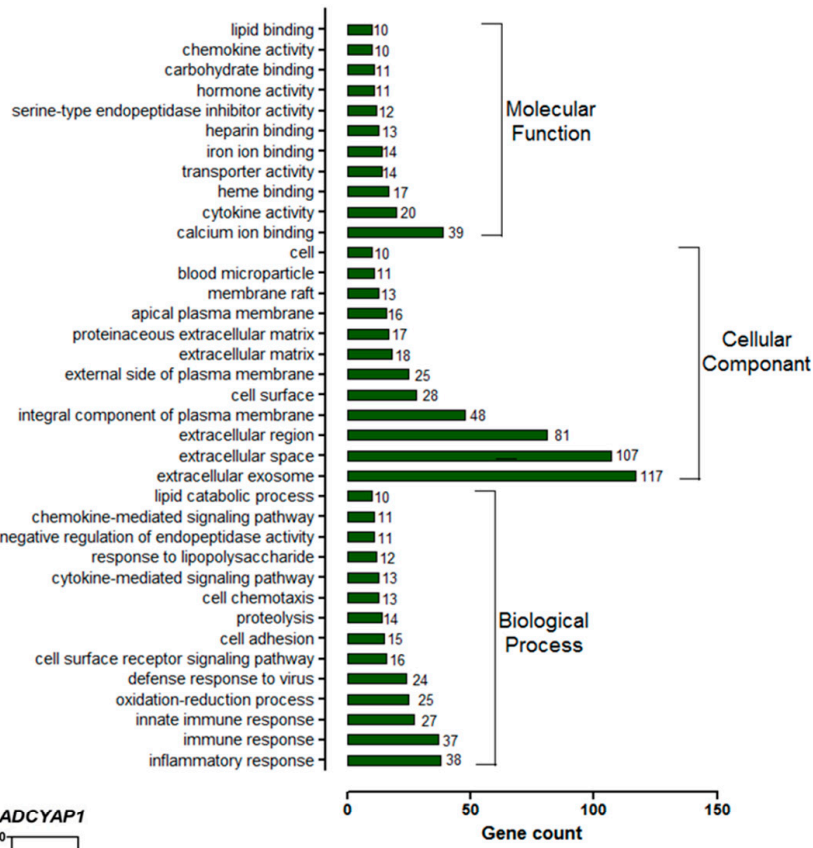

Figure 1. Gene expression profiling of the small intestine of pigs treated with the ethanol extract of dried E. cava (EEEC). (A) Venn diagram of genes up- or downregulated at least two-folds after EEEC treatment, compared with the control levels. (B) GO terms assigned to "biological processes", "cellular components", and "molecular functions" ( $p<0.01)$. (C) Kyoto Encyclopedia of Genes and Genomes (KEGG) pathway analysis of the same gene sets $(p<0.01)$. (D) Quantitative analysis of the top 10 differentially expressed genes (DEGs; $\mathrm{n}=3$ ). Relative expression levels were normalized to those of glyceraldehyde 3-phosphate dehydrogenase (GAPDH). Error bars indicate standard error of triplicate analyses. ${ }^{*} p<0.05,{ }^{* *} p<0.01$.

We verified the expression of the top 10 DEGs in the small intestine with or without EEEC treatment through qRT-PCR (Figure 1D) and confirmed that lectin, galactoside-binding, soluble $13(p<0.01)$, pheromaxein C subunit ( $p<0.01)$, PDX1 ( $p<0.01)$, solute carrier family 22 member A7 $(p<0.01)$, adenylate cyclase activating polypeptide $1(p<0.01)$, resistin $(p<0.05)$, heparin-binding epidermal growth factor-like growth factor $(H B E G F)(p<0.05)$, RNA-binding protein $7(p<0.06)$, Spalt-like transcription factor 1 $(p<0.05)$, and $A$ disintegrin and metalloproteinase with thrombospondin motifs $20(p<0.05)$ were more strongly upregulated in the EEEC-treated group as compared with the untreated group (Figure 1D).

\subsection{Eckol Induces PDX1 and HBEGF Expression}

We next evaluated the toxicity of EEEC, eckol, dieckol, and phlorofucofuroeckol in IPEC-J2 cells while using a cell viability assay. Pretreatment for $24 \mathrm{~h}$ with $50 \mu \mathrm{M}$ of EEEC, $100 \mu \mathrm{M}$ of eckol and dieckol, or $200 \mu \mathrm{M}$ of phlorofucofuroeckol reduced cell viability (Figure 2A). Based on these results, $10 \mu \mathrm{M}$ of EEEC, $50 \mu \mathrm{M}$ of eckol and dieckol, and $100 \mu \mathrm{M}$ of phlorofucofuroeckol were selected as the safe dosages for subsequent experiments. HBEGF expression was induced by treatment with $10 \mu \mathrm{M}$ of EEEC $(p<0.01)$ and $50 \mu \mathrm{M}$ of eckol $(p<0.05)$ (Figure $2 \mathrm{~B})$. These results indicate that eckol is the main component of EEEC that mediates differential gene expression. 
A
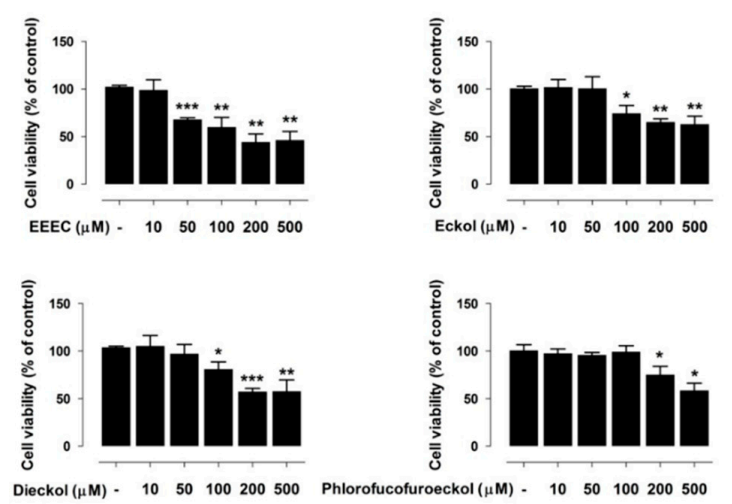

B
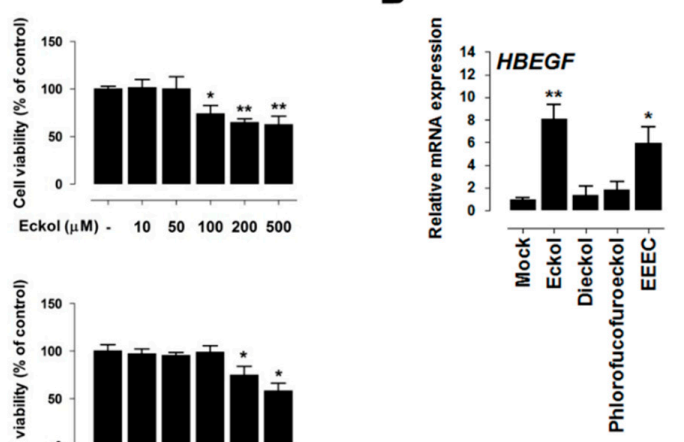

Figure 2. Toxicity of ethanol extracted of dried E. cava (EEEC), eckol, dieckol, and phlorofucofuroeckol (A) EEEC, eckol, dieckol, and phlorofucofuroeckol toxicity was evaluated by performing a cell viability assay using IPEC-J2 cells incubated with the indicated concentrations of each compound for $24 \mathrm{~h}$. (B) Heparin-binding epidermal growth factor-like growth factor (HBEGF) expression in the treatment groups (EEEC, eckol, dieckol, and phlorofucofuroeckol). In qRT-PCR analysis, target gene expression levels were normalized to those of glyceraldehyde 3-phosphate dehydrogenase (GAPDH). Error bars indicate standard error of triplicate analyses. ${ }^{*} p<0.05,{ }^{* *} p<0.01,{ }^{* * *} p<0.001$.

Indeed, eckol incubation with different concentrations $(10 \mu \mathrm{M}, 20 \mu \mathrm{M}, 50 \mu \mathrm{M}, 100 \mu \mathrm{M}$, and $200 \mu \mathrm{M})$ for $24 \mathrm{~h}$ resulted in a concentration-dependent increase in PDX1 (Figure 3A,B) and HBEGF (Figure 3C,D) mRNA and protein levels.

A

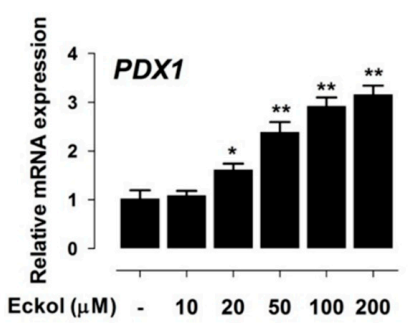

C

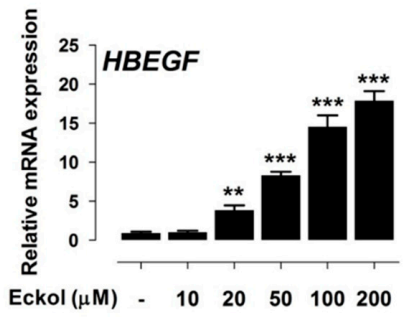

B

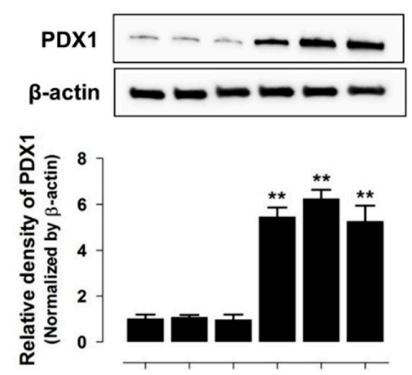

Eckol $(\mu \mathrm{M})$ - $\quad 10 \quad 20 \quad 50 \quad 100200$

D

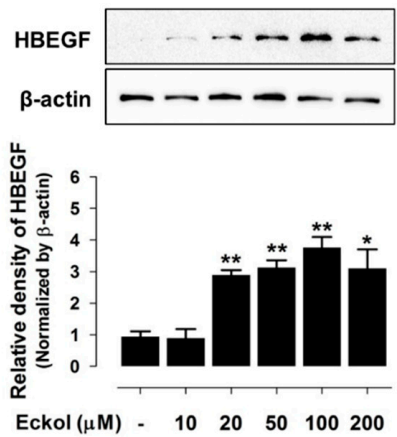

Figure 3. Eckol induces PDX1 and HBEGF expression. PDX1 mRNA (A) and protein (B) expression in cells treated with eckol at different concentrations $(0 \mu \mathrm{M}, 10 \mu \mathrm{M}, 20 \mu \mathrm{M}, 50 \mu \mathrm{M}, 100 \mu \mathrm{M}$, and $200 \mu \mathrm{M})$. HBEGF mRNA (C) and protein (D) expression in cells treated with various concentrations of eckol. Protein band intensity in the Western blot analysis was quantified using the threshold function of the ImageJ software. For qRT-PCR analysis, target gene expression levels were normalized to those of glyceraldehyde 3-phosphate dehydrogenase (GAPDH). Error bars indicate standard error of triplicate analyses. ${ }^{*} p<0.05,{ }^{* *} p<0.01,{ }^{* * *} p<0.001$. 


\subsection{Eckol-Mediated Induction of PDX1 Regulates HBEGF Expression}

We cloned different lengths of porcine $H B E G F$ gene promoter sequences into the firefly luciferase plasmid to evaluate the transcriptional activity of PDX1 in response to eckol treatment in order to investigate whether PDX1 activation directly regulates HBEGF expression in intestinal epithelial cells in response to eckol treatment. Luciferase activity was stimulated in the presence of the -2000 , -1500 , and -1000 sequences relative to that of the control (Figure 4A). Three regions $(-954,-790$, and -767 ) of the PDX1 binding sequence (TAAT) were identified between -1000 and -500 (Figure 4B). The deletion of the PDX1 binding sequence upstream of -790 reduced luciferase activity as compared with the control levels (Figure 4C), suggesting that it is essential for the HBEGF promoter's basal transcriptional activity.

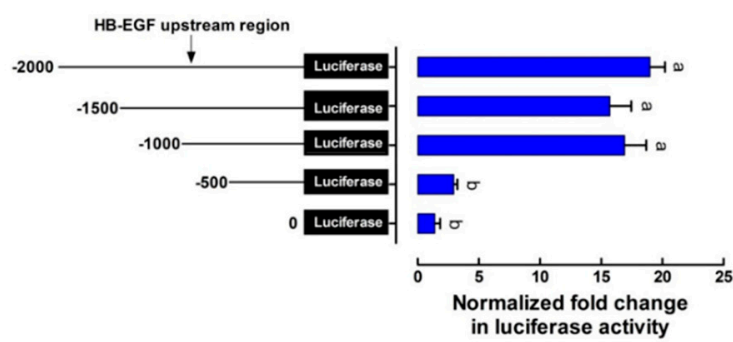

B

-1000 ICCGATGOCG GMGCCTGGG MITATMCC, CATAGITCM MMICT IAAT GGAGACTATG TCCACTGAGA CMMGATGGG GAGMGOCTC TCCAGCGGCT PDX1 binding site (-954)

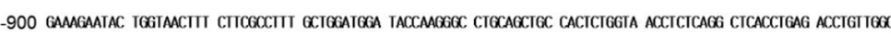

PDX1 binding site (-790) PDX1 binding site (-767)

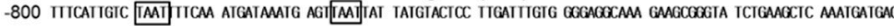

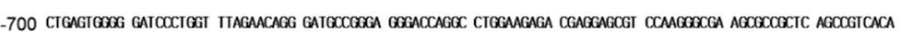
$-600$

Translation start site

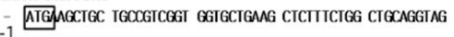

C

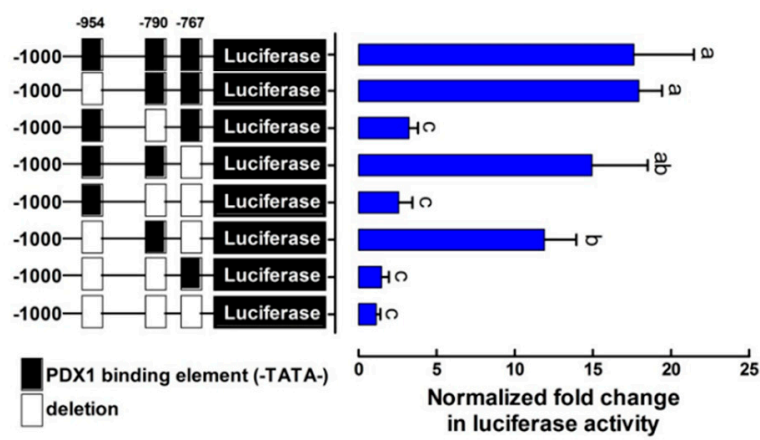

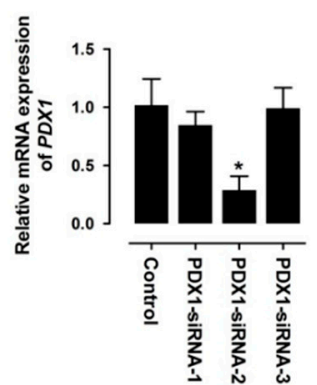

E

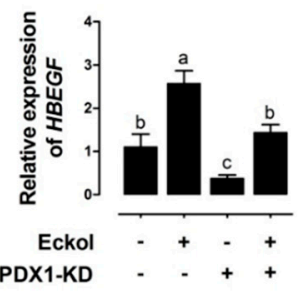

Figure 4. Eckol-induced PDX1 regulates HBEGF expression. (A) Activity of HBEGF upstream region. IPEC-J2 cells were transfected with DNA sequences of different lengths (-2000, $-1500,-1000$, and -500$)$ comprising the upstream region of $\operatorname{HBEGF}(\mathrm{n}=3)$. (B) Upstream sequence of the putative core region of the HBEGF promoter. Sequence numbering is relative to the transcription start site. Putative PDX1 binding sites (TAAT) are boxed and labeled above (upstream of $-954,-790$, and -767 ). (C) Deletion assay of putative PDX1 binding sites. Sequences in which the deleted binding sites (upstream of -954, -790, and -767) were transfected into IPEC-J2 cells ( $\mathrm{n}=3$ ). (D) PDX1 knockdown assay. The siRNA-mediated suppression of PDX1 in IPEC-J2 cells was confirmed using qRT-PCR. (E) Relative HBEGF expression in PDX1-silenced IPEC-J2 cells treated with eckol. Relative luciferase activity was calculated as the ratio of firefly to Renilla luciferase, and the relative expression level was normalized to that of glyceraldehyde 3-phosphate dehydrogenase (GAPDH). Error bars indicate standard error of triplicate analyses. ${ }^{*} p<0.05$. Lower-case letters indicate significant differences among treatments based on Duncan's multiple range test. 
Next, we examined whether PDX1 knockdown affects HBEGF expression. Three different siRNA sequences (siRNA-1, siRNA-2, and siRNA-3 with knockdown efficiencies of $13.32 \% \pm 14.96 \%$, $78.47 \% \pm 16.99 \%(p<0.05)$, and $5.35 \% \pm 23.06 \%$, respectively) against porcine PDX1 reduced PDX1 expression in IPEC-J2 cells more efficiently than a non-specific siRNA with no homology to porcine sequences (Figure 4D). According to these results, we used PDX1-siRNA-2 for subsequent experiments. After eckol treatment, PDX1 knockdown reduced HBEGF expression (Figure 4E). Taken together, our results indicate that PDX1 directly regulates $H B E G F$ expression by binding to the promoter region upstream of -790 .

\subsection{Eckol Enhances Intestinal Barrier Function and Promotes Wound Healing}

We examined phosphoinositide 3-kinase (PI3K)/AKT activation (Figure 5A) and P38 (Figure 5B) signaling pathways to investigate the mechanism by which eckol modulates the expression and function of HBEGF in the intestine. Treating IPEC-J2 cells with eckol and HBEGF increased AKT phosphorylation, whereas treatment with the PI3K inhibitor LY294002 decreased AKT phosphorylation after eckol and HBEGF treatment, as compared with that in the untreated controls. Eckol and HBEGF treatment also increased P38 phosphorylation, but it was reversed after treatment with the P38 mitogen-activated protein kinase (MAPK) inhibitor SB202190.

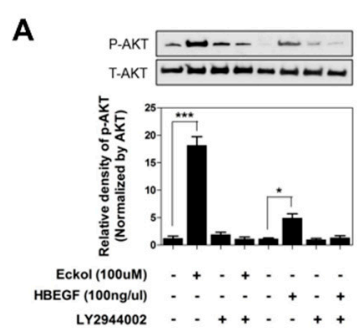

E

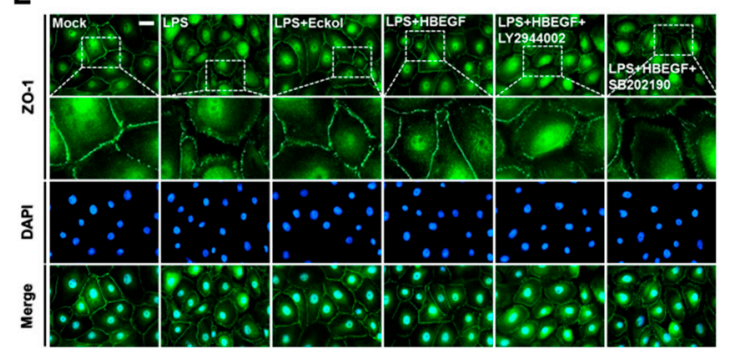

B

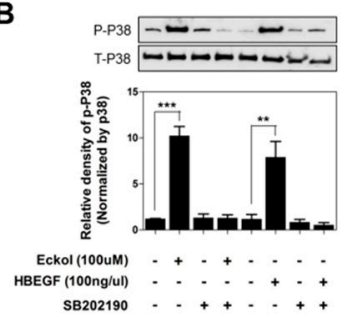

C

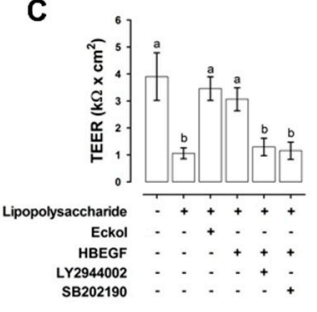

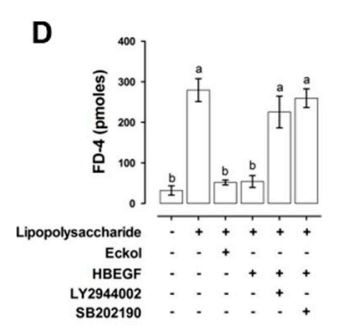

F

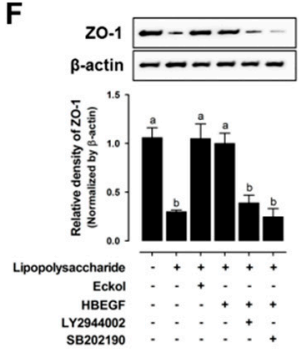

Figure 5. Effects of eckol on intestinal barrier function. Activation of PI3K/AKT (A) and P38 (B) signaling pathways in IPEC-J2 cells treated with eckol and HBEGF for $2 \mathrm{~h}$ under lipopolysaccharide (LPS) challenge. AKT (Ser473) and P38 (Thr180/Tyr182) phosphorylation was evaluated by Western blotting. Protective effects of eckol and HBEGF on intestinal barrier function in IPEC-J2 cells under LPS challenge, as determined by TEER quantification (C), and the permeability of fluorescein isothiocyanate-FD-4 (D) $(\mathrm{n}=3)$. ZO-1 expression upon eckol and HBEGF treatment under LPS challenge was evaluated by immunofluorescence analysis (E) and Western blotting (F). Nuclei were stained with 4',6-diamidino-2-phenylindole (DAPI). IPEC-J2 cells were treated with eckol and HBEGF under LPS challenge with or without PI3K/AKT (LY2944002) and P38 (SB202190) inhibitors. Error bars indicate standard error of triplicate analyses. ${ }^{*} p<0.05,{ }^{* *} p<0.01,{ }^{* * *} p<0.001$. Lower-case letters indicate significant differences among treatments that are based on Duncan's multiple range test.

Next, we examined the effects of eckol and HBEGF on intestinal barrier function by evaluating TEER, permeability, and tight junction protein expression in IPEC-J2 cells. LPS treatment for $1 \mathrm{~h}$ decreased TEER to less than that in the untreated control cells, an effect that was reversed after eckol and HBEGF treatment (Figure 5C). In contrast, the application of LY294002 and SB202190 reduced TEER in LPS-treated cells. LPS exposure for $1 \mathrm{~h}$ also reduced the permeability to FD-4, whereas 
it was reversed by eckol and HBEGF treatment (Figure 5D) and intensified by applying LY294002 and SB202190. Immunocytochemical and Western blot analyses showed that ZO-1 expression was downregulated relative to the control levels in IPEC-J2 cells that were treated with LPS for $1 \mathrm{~h}$, but it was upregulated by eckol and HBEGF treatment and abrogated by LY294002 and SB202190 treatment (Figure 5E,F).

Intestinal wound healing depends on a precise balance among migration, proliferation, and differentiation of epithelial cells adjacent to the wound. Here, we investigated the effects of eckol and HBEGF on intestinal wound healing by assessing cell proliferation and migration while using IPEC-J2 cells. LPS treatment reduced cell growth, whereas adding eckol and HBEGF to the culture media increased cell proliferation (Figure 6A). Similarly, eckol and HBEGF treatment enhanced the migratory capacity of LPS-challenged cells, an effect that was diminished by applying LY294002 and SB202190 (Figure 6B).

A

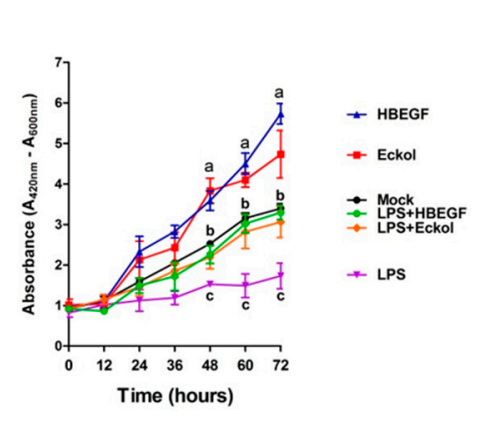

B

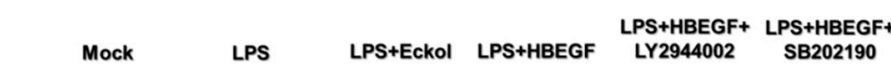

C

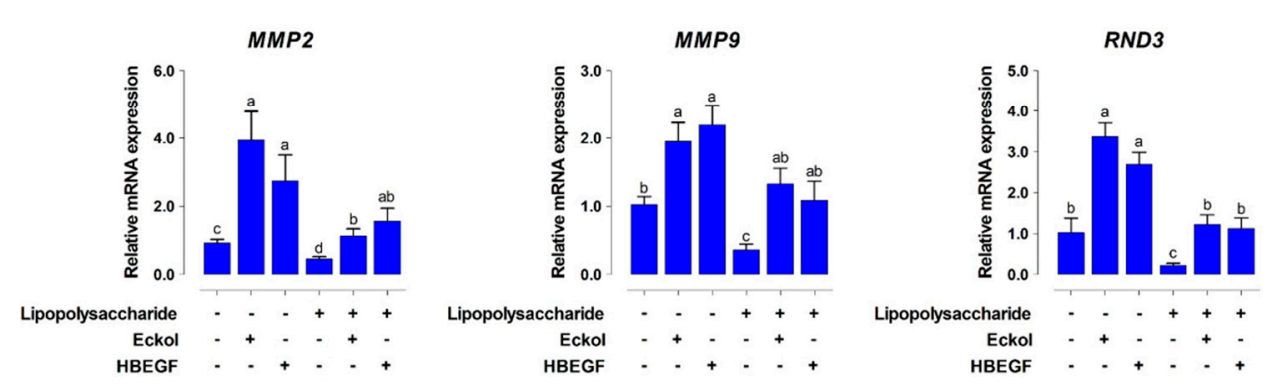

Figure 6. Eckol promotes intestinal wound healing through HBEGF. (A) Cell proliferation was assessed at $12 \mathrm{~h}, 24 \mathrm{~h}, 36 \mathrm{~h}, 48 \mathrm{~h}, 60 \mathrm{~h}$, and $72 \mathrm{~h}$ using the water-soluble tetrazolium-1 assay (n = 3) (B) Migration was assessed at $0 \mathrm{~h}, 6 \mathrm{~h}$, and $12 \mathrm{~h}$ using a wound-healing assay $(\mathrm{n}=3)(\mathrm{C})$ Relative expression levels of cell migration-related genes were analyzed using qRT-PCR in eckol- and HBEGF-treated IPEC-J2 cells under LPS challenge with or without PI3K/AKT (LY2944002) and P38 (SB202190) inhibitors. Error bars indicate standard error of triplicate analyses. Lower-case letters indicate significant differences $(p<0.05)$ among treatments, based on Duncan's multiple range test.

We analyzed the expression of wound healing-related genes, such as matrix metalloproteinase $(M M P)$ 2, MMP9, and Rho family GTPases (RND) 3 in IPEC-J2 cells with or without eckol and HBEGF treatment to determine the effects of eckol and HBEGF on intestinal epithelial cell differentiation (Figure 6C). The MMP2, MMP9, and RND3 levels were downregulated by LPS treatment relative to that in the untreated control cells, but they were increased by eckol and HBEGF treatment.

\subsection{Eckol Protects against Oxidative Stress in the Intestine}

We analyzed heme oxygenase (HO)-1 and manganese superoxide dismutase (MnSOD) expression, as well as reactive oxygen species (ROS) production, in IPEC-J2 cells to investigate the effects of eckol on intestinal oxidative stress. $\mathrm{H}_{2} \mathrm{O}_{2}$ treatment for $1 \mathrm{~h}$ reduced the $\mathrm{HO}-1$ levels relative to that in 
untreated cells, but this was reversed by eckol treatment, and LY294002 had a similar effect (Figure 7A). The $\mathrm{H}_{2} \mathrm{O}_{2}$-treated cells showed higher DCF fluorescence as compared with that in the untreated control, and SB202190 treatment also increased DCF fluorescence; however, this was reversed by eckol treatment (Figure 7B). Thus, eckol alleviates $\mathrm{H}_{2} \mathrm{O}_{2}$-induced oxidative stress through PI3K/AKT signaling.

A

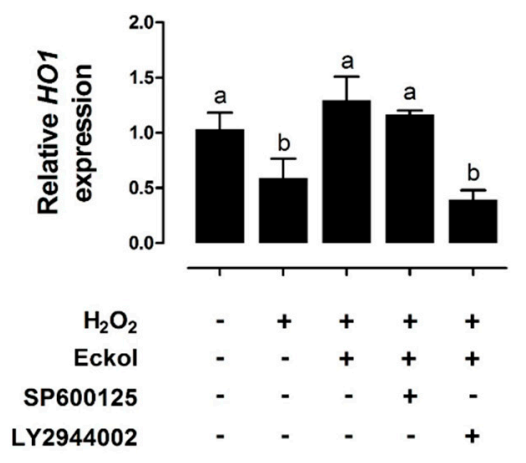

C

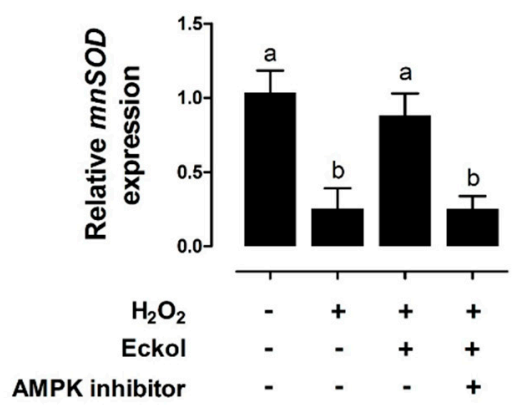

B

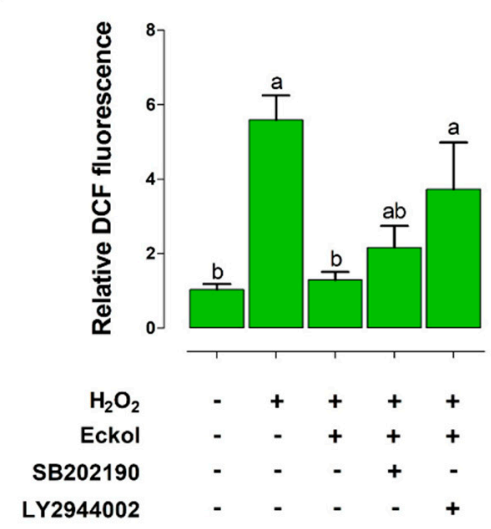

D

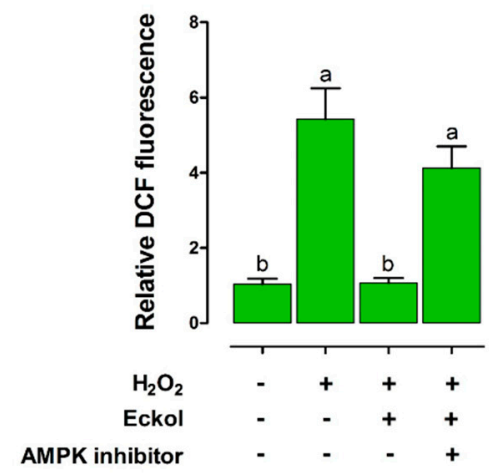

Figure 7. Eckol protects against $\mathrm{H}_{2} \mathrm{O}_{2}$-induced oxidative stress in IPEC-J2 cells. Relative HO-1 (A) and $\mathrm{MnSOD}$ expression levels $(\mathrm{C})$ were evaluated through qRT-PCR $(\mathrm{n}=3)$. Relative cellular ROS ratio was determined through $2^{\prime}, 7^{\prime}$-dichlorofluorescein (DCF) fluorescence analysis with or without PI3K/AKT (LY2944002), P38 (SB202190) (B), or 5'-AMP-activated protein kinase (AMPK) (D) inhibitor $(n=3)$ in eckol-treated cells exposed to $\mathrm{H}_{2} \mathrm{O}_{2}$-induced oxidative stress. Lower-case letters indicate significant differences $(p<0.05)$ among treatments, based on Duncan's multiple range test.

$M n S O D$ expression was decreased, whereas DCF fluorescence was increased in $\mathrm{H}_{2} \mathrm{O}_{2}$-treated IPEC-J2 cells relative to control cell levels. Eckol treatment restored MnSOD levels and reduced DCF fluorescence, whereas 5'-AMP-activated protein kinase (AMPK) inhibitor treatment reversed these effects (Figure $7 \mathrm{C}, \mathrm{D}$ ). These results suggest that eckol alleviates $\mathrm{H}_{2} \mathrm{O}_{2}$-induced oxidative stress through AMPK signaling.

\subsection{EEEC Supplementation Improves Intestinal Function in Pigs during Weaning}

EEEC was administered as a dietary supplement to pigs in the weaning period, and we evaluated their growth, as well as the serum levels of stress markers, in order to investigate the in vivo effects of EEEC. Average daily gain (ADG) was higher in pigs fed with $0.05 \%$ and $0.1 \%$ EEEC than that in pigs fed with the control diet during phase I (days 1-7) and phase II (days 8-21) $(p<0.05$; Figure 8A). At the end of the feeding trial, (day 42), the cortisol levels were lower in pigs that were fed with $0.05 \%(p<0.05)$ and $0.1 \%(p<0.05)$ EEEC, and epinephrine and norepinephrine levels were reduced in pigs fed with $0.1 \%$ EEEC ( $p<0.05$; Figure 8 B). Pigs fed with $0.05 \%$ and $0.1 \%$ EEEC also had lower serum superoxide dismutase (SOD) and glutathione peroxidase (GPx) levels and higher serum 
malondialdehyde (MDA) levels on days 7 and 21, as compared with control animals ( $p<0.05$; Figure 8C). Thus, EEEC supplementation improves growth performance and reduces stress in pigs during the weaning period.

\section{A}

Phase I (1 7d)

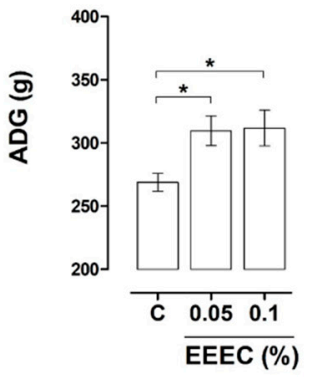

Phase II (7 21d)

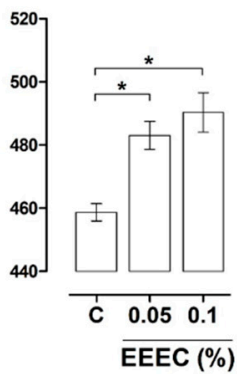

Phase III (21 42d)

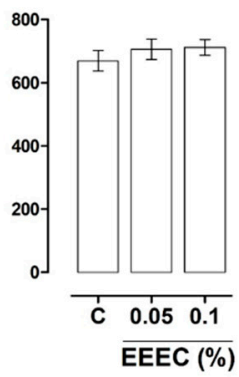

B
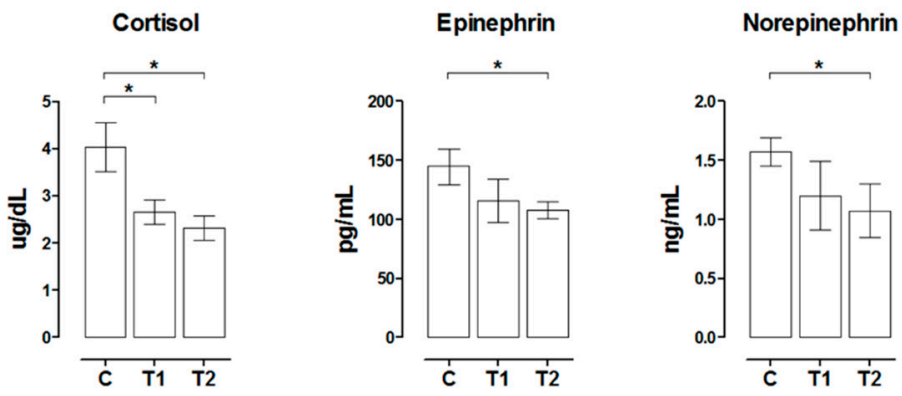

C
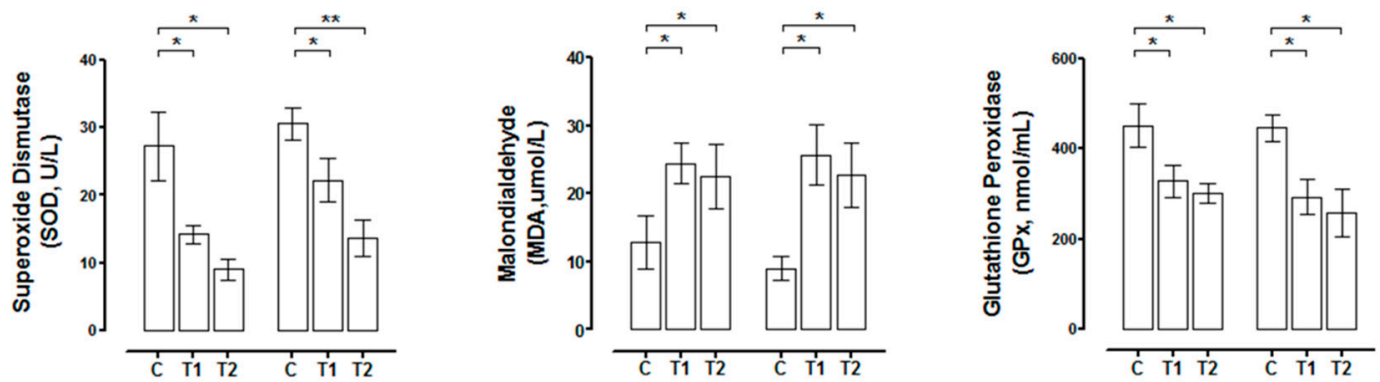

Figure 8. In vivo feeding trial during the suckling-to-weaning transition in pigs. The pigs were sorted into pens ( $\mathrm{n}=5$ per pen, eight pens per treatment) and assigned to the following feeding groups: corn-soybean meal (C, control); control + 0.05\% EEEC (T1); control + 0.1\% EEEC (T2). (A) Dietary ethanol extract of dried E. cava (EEEC) supplementation improved average daily gain (ADG) in pigs during three developmental phases (days 1-7, 7-21, and 21-42). Serum levels of stress-related hormones, such as cortisol, epinephrine, and norepinephrine (B); and oxidative stress markers, such as superoxide dismutase (SOD), malondialdehyde (MDA), and glutathione peroxidase (GPx) (C), were determined through an enzyme-linked immunosorbent assay $(n=10)$. Error bars indicate the standard error of triplicate analyses. ${ }^{*} p<0.05$ and ${ }^{* *} p<0.01$

\section{Discussion}

The suckling-to-weaning transition is associated with various sources of stress, such as maternal separation, mixing, transportation/relocation, and dietary changes. These stressors collectively contribute to intestinal dysfunction, including intestinal villus atrophy, crypt hyperplasia, and increased intestinal 
permeability, which results in reduced feed intake and retarded growth, as well as increased disease susceptibility. Therefore, this period represents a major bottleneck in livestock production [1,3]. To minimize intestinal dysfunction during this transition, nutritional strategies, such as manipulating the dietary protein and non-starch polysaccharide contents, as well as adding antibiotics, zinc, probiotics, prebiotics, and polyphenols to livestock diet, have been applied to pig production [15,24]. Phlorotannins, such as eckol, dieckol, and phlorofucofuroeckol found in brown algae, have protective effects against oxidative stress-induced mitochondrial dysfunction and radiation-induced intestinal injury $[25,26]$. In the present study, we investigated the mechanism of action of EEEC in intestinal development during the suckling-to-weaning transition.

Our transcriptome analysis identified 639 upregulated and 251 downregulated genes in response to EEEC treatment. These DEGs were enriched in various GO categories, and the expression patterns of the top 10 genes were confirmed in the small intestine. Consistent with our results, previous studies demonstrated that polyphenols alter the expression of genes that are related to "Wnt signaling", "chemokine activity", "cytokine activity", "bone morphogenetic protein", "TGF- $\beta$ signaling", "apoptosis", "adipogenesis", "cytokine response", "inflammatory response", and "proliferation" $[27,28]$. We also analyzed PDX1 and HBEGF expression in intestinal epithelial cells treated with each phlorotannin to investigate the role of individual EEEC components. Based on the results, eckol-induced PDX1 and HBEGF expression to a greater extent than dieckol and phlorofucofuroeckol; hence, eckol was examined to further investigate its regulatory functions in small intestinal development.

PDX1 is a homeodomain transcription factor and key regulator of genes that are involved in pancreatic development and intestinal differentiation $[29,30]$ and, along with (sex-determining region Y)-box 2 and caudal type homeobox 2, it regulates the differentiation of enterocytes, Brunner's gland cells, and enteroendocrine cells in the proximal intestine by modulating genes that are related to lipid metabolism and iron absorption [31-33]. We found that eckolinduced PDX1 activates HBEGF expression, which is implicated in wound healing, heart development, and gut protection [34-36]. HBEGF protects against intestinal hypoxia and ischemia/reperfusion injury, as well as necrotizing enterocolitis by suppressing pro-inflammatory cytokine-induced apoptosis and ROS production [37-39]. In addition to PDX1, HBEGF expression is regulated by nuclear factor- $\mathrm{kB}$, specificity protein 1 , and myogenic differentiation transcription factors in diverse biological processes, such as inflammation, homeostasis, and development [40-42]. In the present study, the PDX1 binding site (C/TTAATG) was detected in the upstream region $(-954,-790$, and -767$)$ of the porcine HBEGF gene. Deletion analysis confirmed that PDX1 directly binds the sequence upstream of -790 to regulate basal transcriptional HBEGF activity in small intestinal epithelial cells.

The intestinal epithelium restricts paracellular penetration of potentially toxic substances that cause intestinal inflammation and injury through the tight and adherens junction complexes. It also supports wound repair by stimulating epithelial cell migration, proliferation, and differentiation [43-45]. HBEGF treatment was found to increase TEER and decrease FD-4 penetration that results from LPS-induced intestinal barrier dysfunction by increasing the expression of tight junction proteins, such as ZO-1 and occludin. Our results agree with those of earlier studies that reported that HBEGF knockout mice have shorter villi and higher mucosal permeability, as well as perturbed intestinal wound healing, which was reversed by HBEGF overexpression $[46,47]$. These findings suggest that HBEGF serves as a prophylactic or therapeutic agent for preventing or treating intestinal disorders, such as hypo-perfusion injury and peritonitis-induced sepsis. The extracellular signal-regulated kinase (ERK)1/2 MAPK, PI3K/AKT, nucleotide-binding oligomerization domain-containing protein 1/2, c-Jun N-terminal kinase (JNK)1/2, and STAT signaling pathways are involved in intestinal barrier function and wound healing $[11,44,48]$. The present study showed that HBEGF alleviated LPS-induced intestinal dysfunction through PI3K/AKT and P38 signaling pathway activation. In a previous report, HBEGF enhanced wound healing from intestinal ischemia/reperfusion injury through PI3K/AKT and MAPK/ERK kinase/ERK1/2 activation [49]. Our results also provide evidence that HBEGF preserves 
the barrier function of LPS-stimulated intestinal cells and promotes wound healing through P38 and PI3K/AKT signaling.

The present study confirmed that the eckol in EEEC reduces oxidative stress in intestinal epithelial cells. Oxidative stress that is caused by ROS or reactive nitrogen species is linked to various intestinal disorders, such as IBD, gastroduodenal ulcers, and colon cancer [50,51]. Polyphenols protects cells against oxidative stress by eliminating free radicals [52]. Eckol attenuates oxidative stress by upregulating transcription factors, including nuclear respiratory factor and Forkhead box O3a, which directly regulate ROS-scavenging enzymes, such as HO-1 and MnSOD through the NRF2/JNK, ERK, PI3K/AKT, and AMPK signaling pathways $[25,53,54]$. In the present study, we showed that eckol alleviates $\mathrm{H}_{2} \mathrm{O}_{2}$-induced oxidative stress by stimulating $\mathrm{HO}-1$ and $\mathrm{MnSOD}$ expression through the PI3K/AKT, P38, and AMPK signaling pathways, which is consistent with the findings of previous studies. Based on these results, we propose that eckol can be used as a therapeutic agent to alleviate oxidative stress.

We also investigated the in vivo effects of EEEC on growth, serum stress hormone, and oxidative stress levels in pigs during the weaning period. Dietary EEEC supplementation improved growth performance, and reduced the levels of stress hormones (cortisol, epinephrine, and norepinephrine) and antioxidants (SOD and GPx). The positive effect of eckol on growth might be due to its ability to improve intestinal dysfunction and reduce oxidative stress. The growth of piglets during the suckling-to-weaning transition is directly related to the total market days of the animal; for example, the number of days to market was approximately $6-10$ days shorter for piglets with higher ADG ( $227 \mathrm{~g} /$ day) on the first week after weaning as compared with those with lower ADG (150 g/day) [1]. In the present study, EEEC as a feed additive supplement improved ADG at phases I (1-7 days) and II (7-21 days), but not at phase III (21-42 days). Based on this result, it is possible that EEEC was only effective during phase I and II development, since these phases are associated with rapid intestinal changes; however, it was not effective at phase III, because intestinal development has returned to normal. Thus, further studies are warranted in order to determine whether or not EEEC supplementation is directly related to a decrease in total market days in terms of pig production.

\section{Materials and Methods}

\subsection{Animals and Feeding Trial}

A total of 160 crossbred weaned pigs ([Yorkshire $\times$ Landrace] $\times$ Duroc) with an average body weight of $8.23 \pm 0.93 \mathrm{~kg}$ were used in a six-week feeding trial. The pigs were sorted into pens ( $\mathrm{n}=5$ per pen, eight pens per treatment) and into the following feeding groups: corn-soybean meal (C, control); control $+0.05 \%$ EEEC (T1); and, control + 0.1\% EEEC (T2). Body weight was recorded at the beginning of the experiment (day 0 ) and on days 7,21 , and 42 , and feed consumption was recorded for each pen in order to calculate the ADG and average daily feed intake in the experiment. Blood samples $(10 \mathrm{~mL})$ were collected from 10 random pigs per treatment group at the end of the feeding trial. Serum was separated through centrifugation at $4000 \times g$ for $30 \mathrm{~min}$ at $4{ }^{\circ} \mathrm{C}$, and the aliquots were stored at $4{ }^{\circ} \mathrm{C}$ prior to determining the levels of stress hormones, such as cortisol, epinephrine, and norepinephrine; and, oxidative markers, such as SOD, MDA, and GPx.

Serum epinephrine, and norepinephrine levels were quantified through ion-exchange purification, followed by high-performance liquid chromatography with electrochemical detection. The serum SOD, MDA, and GPx levels were determined using enzyme-linked immunosorbent assay commercial kits (all from R\&D Systems, Minneapolis, MN, USA). 


\subsection{Gene Expression Profiling}

During the feeding trial, five piglets per treatment (control and T2) were sacrificed on day 14. The intestinal samples were pooled, frozen in liquid nitrogen, and stored at $-80{ }^{\circ} \mathrm{C}$. Total RNA was isolated using TRIzol reagent (Invitrogen, Carlsbad, CA, USA). Library construction was performed using the SENSE 3' mRNA-Seq Library Prep Kit (Lexogen, Vienna, Austria), according to the manufacturer's instructions. Moreover, an oligo-dT primer containing an Illumina-compatible sequence at the $5^{\prime}$ end was subjected to hybridization to $500 \mathrm{ng}$ of the total RNA, followed by reverse transcription. After the degradation of the RNA template, second-strand synthesis was initiated with a random primer containing an Illumina-compatible linker sequence at the $5^{\prime}$ end. The double-stranded library was purified and amplified, and complete adapter sequences that were required for cluster generation were added. The finished library was purified from the PCR components. High-throughput sequencing was performed by single-end 75 sequencing on a NextSeq 500 instrument (Illumina, San Diego, CA, USA).

\subsection{Quantitative Real-Time ( $q R T)-P C R$ and Western Blotting}

For qRT-PCR, total RNA $(1 \mu \mathrm{g})$ was used as a template for cDNA synthesis using the Maxima First-strand cDNA Synthesis Kit (Life Technologies, Carlsbad, CA, USA). The qRT-PCR primers for each target gene were designed while using the Primer3 program (http://frodo.wi.mit.edu/; Table 1), and the reaction was performed on a 7500 Fast Real-Time PCR System (Applied Biosystems, Foster City, CA, USA) under the following conditions: $94^{\circ} \mathrm{C}$ for $3 \mathrm{~min}$., followed by 40 cycles of $94^{\circ} \mathrm{C}$ for $30 \mathrm{~s}$, $59{ }^{\circ} \mathrm{C}-61{ }^{\circ} \mathrm{C}$ for $30 \mathrm{~s}$, and $72{ }^{\circ} \mathrm{C}$ for $30 \mathrm{~s}$. Target gene expression levels were normalized to that of the housekeeping gene glyceraldehyde 3-phosphate dehydrogenase and calculated using the $2^{-\Delta \Delta \mathrm{CT}}$ method.

For Western blotting, cultured IPEC-J2 cells that were subjected to various treatments were lysed using a lysis buffer (Cell Signaling Technology, Danvers, MA, USA) containing a protease inhibitor cocktail (Roche, Basel, Switzerland). The protein concentration was determined using a Pierce BCA Protein Assay Kit (Thermo Fisher Scientific, Waltham, MA, USA), and the proteins in each sample $(20 \mu \mathrm{g})$ were separated through electrophoresis on a $10 \%$ polyacrylamide gel for $1 \mathrm{~h}$ at $120 \mathrm{~V}$ and transferred to a nitrocellulose membrane (Millipore, Billerica, MA, USA) while using a Mini-PROTEAN Tetra Cell (Bio-Rad, Hercules, CA, USA). After blocking for $1 \mathrm{~h}$, the membrane was incubated overnight at $4{ }^{\circ} \mathrm{C}$ with the appropriate primary antibodies, including anti-HBEGF and anti-PDX1 (both from Antibodies-online GmbH, Aachen, Germany), anti-AKT and anti-P38 (both from Cell Signaling Technology, USA), and anti-ZO-1 (Thermo Fisher Scientific, Waltham MA, USA). After three washes with Tris-buffered saline containing $0.1 \%$ Tween 20, the membrane was incubated for $1 \mathrm{~h}$ at room temperature with the appropriate secondary antibodies. Immunoreactivity was visualized with ECL Select Western blotting detection reagent (GE Healthcare, Little Chalfont, UK), and the protein bands were imaged while using the ChemiDoc imaging system (Bio-Rad, Hercules, CA, USA). Densitometric analysis was performed using the ImageJ software (National Institutes of Health, Bethesda, MD, USA). 
Table 1. List of primers.

\begin{tabular}{|c|c|c|c|c|}
\hline \multirow{2}{*}{ Gene Symbol } & \multirow{2}{*}{ Description } & \multirow{2}{*}{ Accession No. } & \multicolumn{2}{|c|}{ Primer Sequence $\left(5^{\prime}->3^{\prime}\right)$} \\
\hline & & & Forward & Reverse \\
\hline LGALS13 & lectin, galactoside-binding, soluble, 13 & NM_001142841 & CTCTCGCCACAATCTGTGAA & ATCCCGTTTGTGAACTCAGG \\
\hline PHEROC & pheromaxein C subunit & NM_001123161 & CCAGTGATTCCAGCGTAACC & CACTTGCATAAACACGCTGAA \\
\hline SLC22A7 & solute carrier family 22 member 7 & NM_001044617 & GGGAAGGGTTTTTCTGAAGC & TGACAGCCATACTCCATCCA \\
\hline ADCYAP1 & adenylate cyclase activating polypeptide 1 & NM_001001544 & ACAGCAGCGTCTACTGCTCA & TCTCTTTCTTCCGCTGGGTA \\
\hline RETN & resistin $\mathrm{r}$ - $\mathrm{r}-\mathrm{T}$ & NM_213783 & CTCAGGCTTTGCTGTCACTG & GATGCGCAGATGCAAACTTA \\
\hline HBEGF & heparin-binding EGF like growth factor & NM_214299 & CCTACCGAATCTACGGACCA & СTTTCTTTTCCCTCGCTCCT \\
\hline$R B P 7$ & retinol binding protein 7 & NM_001145222 & TGCTGGCCCTAGGTATTGAC & CCAGGCCTTTGTTATCCTCA \\
\hline SAL1 & salivary lipocalin & NM_213814 & ATGTCAATGGCGACAAAACA & AGTTGGAAGCAGCGATCAAT \\
\hline ADAMTS20 & ADAM metallopeptidase with thrombospondin type 1 motif 20 & NM_001257275 & CATCAGCTGTGGCCTGTAGA & CGGCCATACATTCCACTCTT \\
\hline HO1 & HMOX1, heme oxygenase 1 & NM_001004027 & AGCTGTTTCTGAGCCTCCAA & GAACGAAGAGTGGCTCCAAC \\
\hline$m n S O D$ & SOD2, superoxide dismutase 2 & NM_214127 & TTTGGGGCTGTTTTTGTAGG & TGATGGTTTGGGATGGTTTT \\
\hline$M M P 2$ & matrix metallopeptidase 2 & NM_214192 & ACTCCCACTTTGACGACGAT & CGTACTTGCCATCCTTGTCG \\
\hline MMP9 & matrix metallopeptidase 9 & NM_001038004 & TGAAGACGCAGAAGGTGGAT & TTCAGGAGGTCGAAGGTCAC \\
\hline $\mathrm{CDH} 1$ & cadherin 1 & NM_001163060 & CTGTTGCAGGTCTCATCGTG & AACATAGACCGTCCTTGGCA \\
\hline RND3 & Rho family GTPase 3 & NM_214296 & GAGAGAAGAGCCAGCCAGAA & TGTCCCACAGGCTCAATTCT \\
\hline GAPDH & Glyceraldehyde-3-phosphate dehydrogenase & NM_001206359 & ACACCGAGCATCTCCTGACT & GACGAGGCAGGTCTCCCTAA \\
\hline
\end{tabular}




\subsection{Cell Culture and Treatments}

The IPEC-J2 intestinal porcine enterocyte cell line (DSMZ, Braunschweig, Germany) was maintained, as previously described [11]. Moreover, the cells were cultured in high-glucose Dulbecco's Modified Eagle's Medium supplemented with 5\% fetal bovine serum, 1\% insulin-transferrinselenium-X, and $1 \%(v / v)$ penicillin-streptomycin [55]. The cells were maintained at $37{ }^{\circ} \mathrm{C}$ in a humidified atmosphere of $5 \% \mathrm{CO}_{2}$. The IPEC-J2 cells were incubated with different treatments, including recombinant HBEGF (Mybiosource, San Diego, CA, USA), LY2944002 (Cell Signaling Technology, Danvers, MA, USA), SB202190 (Cell Signaling Technology, USA), and the AMPK inhibitor (dorsomorphin dihydrochloride; Santa Cruz Biotechnology, Dallas, TX, USA) at different intervals, as indicated in the figure legends.

\subsection{Immunofluorescence}

IPEC-J2 cell monolayers on glass coverslips were fixed with $4 \%$ paraformaldehyde. After blocking with $2 \%$ bovine serum albumin in phosphate-buffered saline, the cells were incubated overnight at $4{ }^{\circ} \mathrm{C}$ with primary antibodies against zona occludens (ZO)-1 and occludin diluted to a 1:100 ratio. After washing, fluorophore-conjugated secondary antibody (Alexa Fluor 488) was applied for $1 \mathrm{~h}$ at room temperature in the dark. The coverslips were mounted on slides while using Vectashield Antifade Mounting Medium with DAPI (Vector Laboratories, Burlingame, CA, USA), and the images were obtained using a fluorescence microscope.

\subsection{Cell Proliferation and Migration Assays}

To evaluate proliferation, the IPEC-J2 cells were seeded in 96-well plates at a density of $1 \times 10^{4}$ cells/well. Water-soluble tetrazolium-1 cell proliferation reagent (Roche Applied Science, Indianapolis, IN, USA) was added to each well, and dye absorbance at the end of the incubation period was measured at $450 \mathrm{~nm}$ with background subtraction at $690 \mathrm{~nm}$ while using a BioTek Synergy HTTR microplate reader (BioTek Instruments, Winooski, VT, USA).

For the migration assay, the IPEC-J2 cells were cultured with various compounds (eckol, heparin-binding epidermal growth factor-like growth factor (HBEGF), and inhibitors) in 60-mm culture dishes until reaching confluence. A straight scratch was made using a P200 pipette tip across the bottom of the dish, and the migrating cells were photographed at different times.

\subsection{Transepithelial Electrical Resistance (TEER) and Intestinal Permeability}

Confluent IPEC-J2 cell monolayers were cultured in 24-well transwell chambers (polycarbonate membrane, filter pore size $=0.4 \mu \mathrm{m}$, area $=0.33 \mathrm{~cm}^{2}$; Costar) under different treatment conditions for $24 \mathrm{~h}$. The cells were washed twice and incubated with lipopolysaccharide (LPS; $1 \mu \mathrm{g} / \mu \mathrm{L}$ ) for $1 \mathrm{~h}$. TEER was measured using an epithelial voltohmmeter (World Precision Instruments, Sarasota, FL, USA). TEER values were calculated by subtracting the blank filter $(90 \Omega)$ and multiplying by the surface area of the filter. All of the measurements were performed for at least three wells.

The IPEC-J2 cells growing in a confluent monolayer $\left(\geq 1 \mathrm{k} \Omega \mathrm{cm}^{2}\right)$ were treated with different compounds for $24 \mathrm{~h}$. The cells were washed twice and then incubated with LPS for $1 \mathrm{~h}$. After two additional washes, the permeability assay was initiated by adding $500 \mu \mathrm{L}$ of culture media containing $1 \mathrm{mg} / \mathrm{mL}$ fluorescein isothiocyanate-dextran (FD)-4 (Sigma-Aldrich, St. Louis, MO, USA) to the apical chamber, whereas the basolateral chamber was filled with $1.5 \mathrm{~mL}$ of culture media. FD- 4 was allowed to permeate overnight $\left(18 \mathrm{~h}\right.$ at $37^{\circ} \mathrm{C}$ and $\left.5 \% \mathrm{CO}_{2}\right)$ from the apical to the basolateral chamber, and $100 \mu \mathrm{L}$ of the basolateral chamber media was transferred to a 96-well plate in order to measure the extent of FD-4 permeation while using a fluorometer (excitation, $490 \mathrm{~nm}$; emission, $520 \mathrm{~nm}$ ). 


\subsection{Cellular ROS Detection}

The IPEC-J2 cells were seeded in a clear-bottomed 96-well black plate at a density of $1 \times 10^{4}$ cells/well. After eckol and inhibitor treatment with or without $\mathrm{H}_{2} \mathrm{O}_{2}$, the cells were stained with $2.5 \mu \mathrm{M} 2^{\prime}, 7^{\prime}$-dichlorofluorescein (DCF) diacetate, and fluorescence intensity was measured using a fluorometer at excitation and emission wavelengths of 485 and $535 \mathrm{~nm}$, respectively. The values are expressed as fold increase relative to control cell values.

\subsection{Vector construction, Gene Silencing, and Luciferase assay}

For pancreatic and duodenal homeobox (PDX)1 knockdown, the IPEC-J2 cells were transfected with specific small interfering (si)RNAs (Supplemental Table S6) while using RNAiMAX (Invitrogen), according to the manufacturer's instructions. After $24 \mathrm{~h}$, total RNA was extracted and analyzed using qRT-PCR.

For the promoter assay, upstream sequences of the HBEGF gene and the -1000 upstream sequence containing deletions of the PDX1-binding site synthesized by Bioneer (Daejeon, Korea) were sub-cloned into the pGL3-Basic vector. Each vector contained a different length of the HBEGF upstream sequence, and the vector was transfected into the IPEC-J2 cells. After $4 \mathrm{~h}$, the cells were analyzed using a luciferase assay kit (Promega, Madison, WI, USA). Moreover, the cells were re-suspended in $100 \mu \mathrm{L}$ of diluted Passive Lysis Buffer, and the extracts were centrifuged at 13,000 $\mathrm{g}$ for $5 \mathrm{~min}$. Firefly and Renilla luciferase activities in the supernatant were quantified while using a GLOMAX 20/20 luminometer (Promega). The measured values were normalized to Renilla activity.

\subsection{Statistical Analysis}

Data were analyzed by evaluating the differences among treatments using Duncan's multiple range tests through the general linear model function of the SAS software (Systat, Cary, NC, USA). The results are expressed as the mean \pm standard error $(n \geq 3$, where $n$ is the number of replicates). A $p$ value of $<0.05$ was considered to be statistically significant.

\section{Conclusions}

The present study demonstrated that eckol enhanced intestinal function in pigs during the suckling-to-weaning transition by improving intestinal barrier function and wound healing, as well as reducing oxidative stress through PDX1-induced HBEGF expression (Figure 9). Our results indicated that eckol as a feed additive can improve the overall health and growth of livestock by preventing intestinal dysfunction during this critical developmental period, which can subsequently increase livestock marketability. 


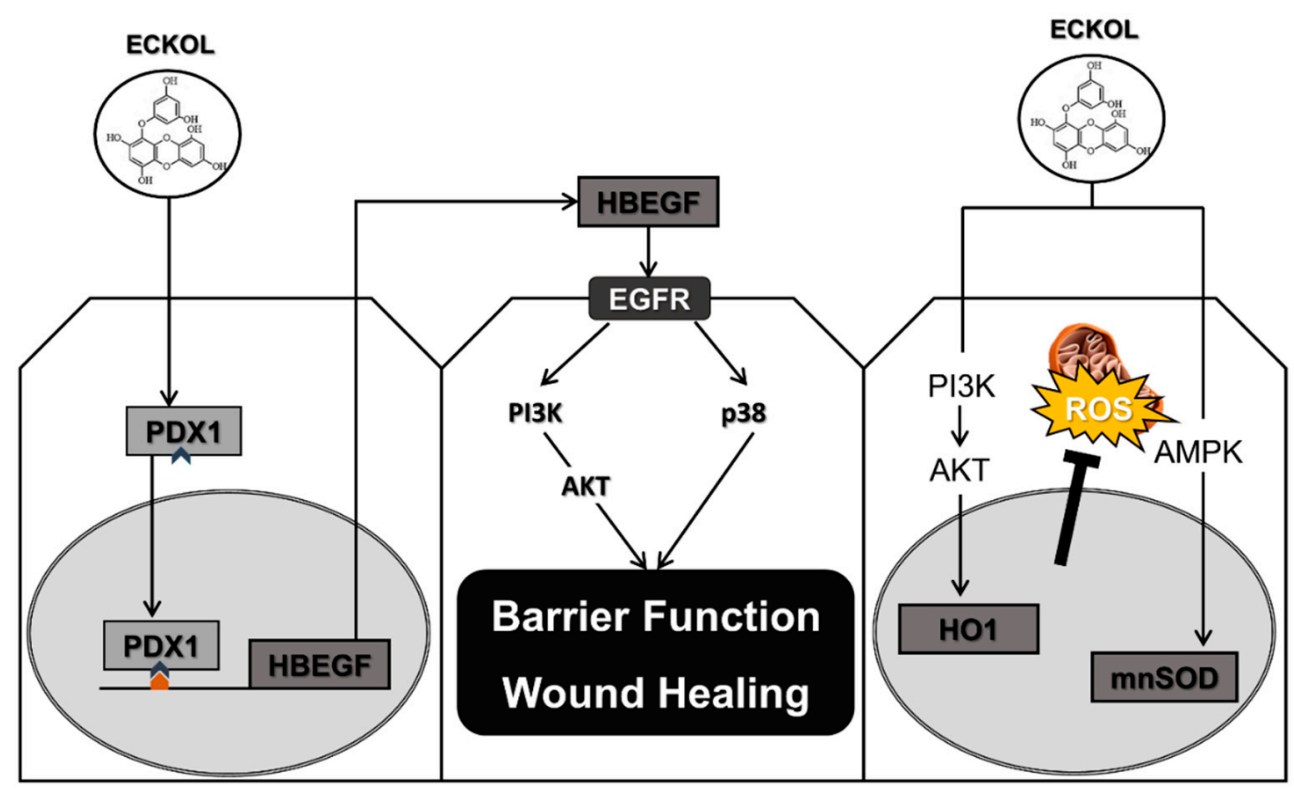

Figure 9. Schematic illustration of the effects of eckol on intestinal development during the suckling-to-weaning transition. Eckol induces PDX1 expression that directly regulates HBEGF expression, leading to enhanced intestinal barrier function, accelerated wound healing, and reduced oxidative stress through the activation of various intracellular signaling pathways.

Supplementary Materials: Supplementary Materials can be found at http://www.mdpi.com/1422-0067/21/13/4755/s1, Table S1: Molecular functions of differentially expressed genes, Table S2: Cellular component of differentially expressed genes, Table S3: Biological process of differentially expressed genes, Table S4: KEGG pathway of differentially expressed genes, Table S5: List of siRNA for PDX-1.

Author Contributions: S.I.L. designed the study, performed the experiments, analyzed and interpreted the data, and wrote the manuscript, I.H.K. supervised the study, interpreted the data, and wrote the manuscript. Both authors have read and agreed to the published version of the manuscript.

Funding: This research was supported by Basic Science Research Program through the National Research Foundation of Korea (NRF) funded by the Ministry of Education (2016R1D1A1B01007639).

Conflicts of Interest: The authors declare no conflict of interest.

\section{Abbreviations}

$\begin{array}{ll}\text { ADG } & \text { average daily gain } \\ \text { AMPK } & \text { amp-activated protein kinase } \\ \text { DEG } & \text { differentially expressed genes } \\ \text { EEEC } & \text { ethanol extract of dried } \text {. cava } \\ \text { HBEGF } & \text { heparin-binding epidermal growth factor-like growth factor } \\ \text { HO-1 } & \text { heme oxygenase-1 } \\ \text { IBD } & \text { inflammatory bowel disease } \\ \text { PDX-1 } & \text { pancreatic and duodenal homeobox 1 } \\ \text { ROS } & \text { reactive oxygen species } \\ \text { JAK-STAT } & \text { Janus kinase-signal transducer and activator of transcription } \\ \text { TEER } & \text { transepithelial/transendothelial electrical resistance } \\ \text { ZO1 } & \text { zona occludens-1 }\end{array}$

\section{References}

1. Campbell, J.M.; Crenshaw, J.D.; Polo, J. The biological stress of early weaned piglets. J. Anim. Sci. Biotechnol. 2013, 4, 19. [CrossRef]

2. Hampson, D.J. Alterations in piglet small intestinal structure at weaning. Res. Veter. Sci. 1986, 40, 32-40. [CrossRef] 
3. Boudry, G.; Peron, V.; Le Huerou-Luron, I.; Lalles, J.P.; Seve, B. Weaning induces both transient and long-lasting modifications of absorptive, secretory, and barrier properties of piglet intestine. J. Nutr. 2004, 134, 2256-2262. [CrossRef] [PubMed]

4. Montagne, L.; Boudry, G.; Favier, C.; Le Huerou-Luron, I.; Lalles, J.P.; Seve, B. Main intestinal markers associated with the changes in gut architecture and function in piglets after weaning. Br. J. Nutr. 2007, 97, 45-57. [CrossRef]

5. Pacha, J. Development of intestinal transport function in mammals. Physiol. Rev. 2000, 80, $1633-1667$. [CrossRef]

6. Wijtten, P.J.; van der Meulen, J.; Verstegen, M.W. Intestinal barrier function and absorption in pigs after weaning: A review. Br. J. Nutr. 2011, 105, 967-981. [CrossRef]

7. Henderson, P.; van Limbergen, J.E.; Schwarze, J.; Wilson, D.C. Function of the intestinal epithelium and its dysregulation in inflammatory bowel disease. Inflamm. Bowel Dis. 2011, 17, 382-395. [CrossRef]

8. Schneeman, B.O. Gastrointestinal physiology and functions. Br. J. Nutr. 2002, 88, S159-S163. [CrossRef] [PubMed]

9. Xiong, X.; Tan, B.; Song, M.; Ji, P.; Kim, K.; Yin, Y.; Liu, Y. Nutritional intervention for the intestinal development and health of weaned pigs. Front. Veter. Sci. 2019, 6, 46. [CrossRef] [PubMed]

10. Che, D.; Adams, S.; Zhao, B.; Qin, G.; Jiang, H. Effects of dietary L-arginine supplementation from conception to post-weaning in piglets. Curr. Protein Pept. Sci. 2019, 20, 736-749. [CrossRef] [PubMed]

11. Lee, S.I.; Kim, I.H. Nucleotide-mediated SPDEF modulates TFF3-mediated wound healing and intestinal barrier function during the weaning process. Sci. Rep. 2018, 8, 4827. [CrossRef] [PubMed]

12. Cho, J.H.; Zhao, P.Y.; Kim, I.H. Probiotics as a dietary additive for pigs: A review. J. Anim. Veter. Adv. 2011, 10, 2127-2134. [CrossRef]

13. Upadhaya, S.D.; Lee, K.Y.; Kim, I.H. Protected organic Acid blends as an alternative to antibiotics in finishing pigs. Asian-Australas. J. Anim. Sci. 2014, 27, 1600-1607. [CrossRef] [PubMed]

14. Daglia, M. Polyphenols as antimicrobial agents. Curr. Opin. Biotechnol. 2012, 23, 174-181. [CrossRef] [PubMed]

15. Pluske, J.R. Feed- and feed additives-related aspects of gut health and development in weanling pigs. J. Anim. Sci. Biotechnol. 2013, 4, 1. [CrossRef]

16. Shimizu, M. Multifunctions of dietary polyphenols in the regulation of intestinal inflammation. J. Food Drug Anal. 2017, 25, 93-99. [CrossRef]

17. Shin, T.; Ahn, M.; Hyun, J.W.; Kim, S.H.; Moon, C. Antioxidant marine algae phlorotannins and radioprotection: A review of experimental evidence. Acta Histochem. 2014, 116, 669-674. [CrossRef]

18. Lee, H.A.; Lee, J.H.; Han, J.S. A phlorotannin constituent of Ecklonia cava alleviates postprandial hyperglycemia in diabetic mice. Pharm. Biol. 2017, 55, 1149-1154. [CrossRef]

19. Karadeniz, F.; Kang, K.H.; Park, J.W.; Park, S.J.; Kim, S.K. Anti-HIV-1 activity of phlorotannin derivative 8,4"'-dieckol from Korean brown alga Ecklonia cava. Biosci. Biotechnol. Biochem. 2014, 78, 1151-1158. [CrossRef]

20. Kim, R.K.; Uddin, N.; Hyun, J.W.; Kim, C.; Suh, Y.; Lee, S.J. Novel anticancer activity of phloroglucinol against breast cancer stem-like cells. Toxicol. Appl. Pharmacol. 2015, 286, 143-150. [CrossRef]

21. Kwon, H.J.; Ryu, Y.B.; Kim, Y.M.; Song, N.; Kim, C.Y.; Rho, M.C.; Jeong, J.H.; Cho, K.O.; Lee, W.S.; Park, S.J. In vitro antiviral activity of phlorotannins isolated from Ecklonia cava against porcine epidemic diarrhea coronavirus infection and hemagglutination. Bioorganic Med. Chem. 2013, 21, 4706-4713. [CrossRef] [PubMed]

22. Kim, I.H.; Nam, T.J. Enzyme-treated Ecklonia cava extract inhibits adipogenesis through the downregulation of C/EBPalpha in 3T3-L1 adipocytes. Int. J. Mol. Med. 2017, 39, 636-644. [CrossRef] [PubMed]

23. Choi, Y.; Hosseindoust, A.; Goel, A.; Lee, S.; Jha, P.K.; Kwon, I.K.; Chae, B.J. Effects of Ecklonia cava as fucoidan-rich algae on growth performance, nutrient digestibility, intestinal morphology and caecal microflora in weanling pigs. Asian-Australas. J. Anim. Sci. 2017, 30, 64-70. [CrossRef]

24. Heo, J.M.; Opapeju, F.O.; Pluske, J.R.; Kim, J.C.; Hampson, D.J.; Nyachoti, C.M. Gastrointestinal health and function in weaned pigs: A review of feeding strategies to control post-weaning diarrhoea without using in-feed antimicrobial compounds. J. Anim. Physiol. Anim. Nutr. 2013, 97, 207-237. [CrossRef] [PubMed] 
25. Kim, A.D.; Kang, K.A.; Piao, M.J.; Kim, K.C.; Zheng, J.; Yao, C.W.; Cha, J.W.; Hyun, C.L.; Kang, H.K.; Lee, N.H.; et al. Cytoprotective effect of eckol against oxidative stress-induced mitochondrial dysfunction: Involvement of the FoxO3a/AMPK pathway. J. Cell. Biochem. 2014, 115, 1403-1411. [CrossRef]

26. Moon, C.; Kim, S.H.; Kim, J.C.; Hyun, J.W.; Lee, N.H.; Park, J.W.; Shin, T. Protective effect of phlorotannin components phloroglucinol and eckol on radiation-induced intestinal injury in mice. Phytother. Res. 2008, 22, 238-242. [CrossRef] [PubMed]

27. Liu, L.; Lai, C.Q.; Nie, L.; Ordovas, J.; Band, M.; Moser, L.; Meydani, M. The modulation of endothelial cell gene expression by green tea polyphenol-EGCG. Mol. Nutr.Food Res. 2008, 52, 1182-1192. [CrossRef]

28. Vittal, R.; Selvanayagam, Z.E.; Sun, Y.; Hong, J.; Liu, F.; Chin, K.V.; Yang, C.S. Gene expression changes induced by green tea polyphenol (-)-epigallocatechin-3-gallate in human bronchial epithelial 21BES cells analyzed by DNA microarray. Mol. Cancer Ther. 2004, 3, 1091-1099.

29. D'Amour, K.A.; Bang, A.G.; Eliazer, S.; Kelly, O.G.; Agulnick, A.D.; Smart, N.G.; Moorman, M.A.; Kroon, E.; Carpenter, M.K.; Baetge, E.E. Production of pancreatic hormone-expressing endocrine cells from human embryonic stem cells. Nat. Biotechnol. 2006, 24, 1392-1401. [CrossRef]

30. Hashimoto, H.; Kamisako, T.; Kagawa, T.; Haraguchi, S.; Yagoto, M.; Takahashi, R.; Kawai, K.; Suemizu, H. Expression of pancreatic and duodenal homeobox1 (PDX1) protein in the interior and exterior regions of the intestine, revealed by development and analysis of Pdx1 knockout mice. Lab. Anim. Res. 2015, 31, 93-98. [CrossRef]

31. Holland, A.M.; Garcia, S.; Naselli, G.; Macdonald, R.J.; Harrison, L.C. The Parahox gene Pdx1 is required to maintain positional identity in the adult foregut. Int. J. Dev. Biol. 2013, 57, 391-398. [CrossRef]

32. Chen, C.; Sibley, E. Expression profiling identifies novel gene targets and functions for Pdx1 in the duodenum of mature mice. Am. J. Physiol. Liver Physiol. 2012, 302, G407-G419. [CrossRef] [PubMed]

33. Chen, C.; Leavitt, T.; Sibley, E. Intestinal Pdx1 mediates nutrient metabolism gene networks and maternal expression is essential for perinatal growth in mice. Biochem. Biophys. Res. Commun. 2012, 424, 549-553. [CrossRef]

34. Kim, J.M.; Bak, E.J.; Chang, J.Y.; Kim, S.T.; Park, W.S.; Yoo, Y.J.; Cha, J.H. Effects of HB-EGF and epiregulin on wound healing of gingival cells in vitro. Oral Dis. 2011, 17, 785-793. [CrossRef] [PubMed]

35. Iwamoto, R.; Mekada, E. ErbB and HB-EGF signaling in heart development and function. Cell Struct. Funct. 2006, 31, 1-14. [CrossRef] [PubMed]

36. Yang, J.; Su, Y.; Zhou, Y.; Besner, G.E. Heparin-binding EGF-like growth factor (HB-EGF) therapy for intestinal injury: Application and future prospects. Pathophysiology 2014, 21, 95-104. [CrossRef]

37. Kuhn, M.A.; Xia, G.; Mehta, V.B.; Glenn, S.; Michalsky, M.P.; Besner, G.E. Heparin-binding EGF-like growth factor (HB-EGF) decreases oxygen free radical production in vitro and in vivo. Antioxid. Redox Signal. 2002, 4, 639-646. [CrossRef]

38. Michalsky, M.P.; Kuhn, A.; Mehta, V.; Besner, G.E. Heparin-binding EGF-like growth factor decreases apoptosis in intestinal epithelial cells in vitro. J. Pediatr. Surg. 2001, 36, 1130-1135. [CrossRef]

39. Feng, J.; El-Assal, O.N.; Besner, G.E. Heparin-binding EGF-like growth factor (HB-EGF) and necrotizing enterocolitis. Semin. Pediatr. Surg. 2005, 14, 167-174. [CrossRef]

40. Pan, Z.; Wang, Z.; Yang, H.; Zhang, F.; Reinach, P.S. TRPV1 activation is required for hypertonicity-stimulated inflammatory cytokine release in human corneal epithelial cells. Investig. Ophthalmol. Vis. Sci. 2011, 52, 485-493. [CrossRef]

41. Kaneto, H.; Miyagawa, J.; Kajimoto, Y.; Yamamoto, K.; Watada, H.; Umayahara, Y.; Hanafusa, T.; Matsuzawa, Y.; Yamasaki, Y.; Higashiyama, S.; et al. Expression of heparin-binding epidermal growth factor-like growth factor during pancreas development. A potential role of PDX-1 in transcriptional activation. J. Biol. Chem. 1997, 272, 29137-29143. [CrossRef]

42. Miyata, K.; Yotsumoto, F.; Nam, S.O.; Kuroki, M.; Miyamoto, S. Regulatory mechanisms of the HB-EGF autocrine loop in inflammation, homeostasis, development and cancer. Anticancer Res. 2012, 32, 2347-2352. [PubMed]

43. Groschwitz, K.R.; Hogan, S.P. Intestinal barrier function: Molecular regulation and disease pathogenesis. J. Allergy Clin. Immunol. 2009, 124, 3-20. [CrossRef] [PubMed]

44. Iizuka, M.; Konno, S. Wound healing of intestinal epithelial cells. World J. Gastroenterol. 2011, 17, $2161-2171$. [CrossRef] 
45. Tsukita, S.; Furuse, M. The structure and function of claudins, cell adhesion molecules at tight junctions. Ann. N. Y. Acad. Sci. 2000, 915, 129-135. [CrossRef] [PubMed]

46. Yang, J.; Radulescu, A.; Chen, C.L.; Zhang, H.Y.; James, I.O.; Besner, G.E. Heparin-binding epidermal growth factor-like growth factor improves intestinal barrier function and reduces mortality in a murine model of peritonitis. Surgery 2013, 153, 52-62. [CrossRef]

47. Zhang, H.Y.; Radulescu, A.; Besner, G.E. Heparin-binding epidermal growth factor-like growth factor is essential for preservation of gut barrier function after hemorrhagic shock and resuscitation in mice. Surgery 2009, 146, 334-339. [CrossRef]

48. Ran, X.; Li, Y.; Chen, G.; Fu, S.; He, D.; Huang, B.; Wei, L.; Lin, Y.; Guo, Y.; Hu, G. Farrerol ameliorates TNBS-induced colonic inflammation by inhibiting ERK1/2, JNK1/2, and NF-kappaB signaling pathway. Int. J. Mol. Sci. 2018, 19, 2037. [CrossRef]

49. El-Assal, O.N.; Besner, G.E. HB-EGF enhances restitution after intestinal ischemia/reperfusion via PI3K/Akt and MEK/ERK1/2 activation. Gastroenterology 2005, 129, 609-625. [CrossRef]

50. Lam, G.; Apostolopoulos, V.; Zulli, A.; Nurgali, K. NADPH oxidases and inflammatory bowel disease. Curr. Med. Chem. 2015, 22, 2100-2109. [CrossRef]

51. Balmus, I.M.; Ciobica, A.; Trifan, A.; Stanciu, C. The implications of oxidative stress and antioxidant therapies in Inflammatory Bowel Disease: Clinical aspects and animal models. Saudi J. Gastroenterol. 2016, 22, 3-17. [CrossRef] [PubMed]

52. Oz, H.S.; Chen, T.S.; McClain, C.J.; de Villiers, W.J. Antioxidants as novel therapy in a murine model of colitis. J. Nutr. Biochem. 2005, 16, 297-304. [CrossRef]

53. Kim, K.C.; Kang, K.A.; Zhang, R.; Piao, M.J.; Kim, G.Y.; Kang, M.Y.; Lee, S.J.; Lee, N.H.; Surh, Y.J.; Hyun, J.W. Up-regulation of Nrf2-mediated heme oxygenase-1 expression by eckol, a phlorotannin compound, through activation of Erk and PI3K/Akt. Int. J. Biochem. Cell Biol. 2010, 42, 297-305. [CrossRef] [PubMed]

54. Jun, Y.J.; Lee, M.; Shin, T.; Yoon, N.; Kim, J.H.; Kim, H.R. Eckol enhances heme oxygenase-1 expression through activation of Nrf2/JNK pathway in HepG2 cells. Molecules 2014, 19, 15638-15652. [CrossRef] [PubMed]

55. Schierack, P.; Nordhoff, M.; Pollmann, M.; Weyrauch, K.D.; Amasheh, S.; Lodemann, U.; Jores, J.; Tachu, B.; Kleta, S.; Blikslager, A.; et al. Characterization of a porcine intestinal epithelial cell line for in vitro studies of microbial pathogenesis in swine. Histochem. Cell Biol. 2006, 125, 293-305. [CrossRef] [PubMed]

(C) 2020 by the authors. Licensee MDPI, Basel, Switzerland. This article is an open access article distributed under the terms and conditions of the Creative Commons Attribution (CC BY) license (http://creativecommons.org/licenses/by/4.0/). 